Please send trade news information and illustrations to Arveen Bajaj at the $B D J$, Nature Publishing Group, The Macmillan Building, 4-6 Crinan Street, London N 1 9XW.

Trade news is provided as a service to readers using text and images from the manufacturer, supplier or distributor and does not imply endorsement by the $B D J$. Normal and prudent research should be exercised before purchase or use of any product mentioned.

\section{Easing sensitivity}

Sensitrol is a product for the treatment of dentine hypersensitivity and is the

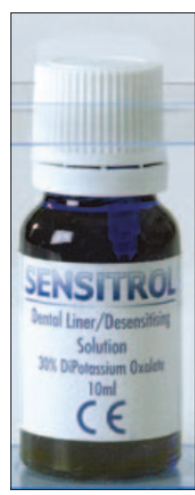

first potassium oxalate desensitiser that is neutral in $\mathrm{PH}$ and contains special patented surface active agents.

This results in complete wetting of the surface of the tooth, delivering the active agent, potassium oxalate to the dentine. The product is now available from Dexcel.

Reader response number 50

\section{New bench-top}

\section{autoclave}

SAL has launched a new combination bench-top autoclave steriliser and washer disinfector, the Asepsys Combi. It has been specifically designed for situations that require compact solutions to small run decontamination applications.

Offering a bench-top autoclave and washer unit standing at $650 \mathrm{~mm} \times 600 \mathrm{~mm}$ $\mathrm{x} 1600 \mathrm{~mm}$, the process used in the Combi is moist steam generated in a pressure vessel. Turbulent air expulsion is then employed for effective sterilisation.

A small printer is connected to the machine enabling the critical operation parameters and performance indicators to be permanently documented for record keeping and traceability.

Reader response number 51

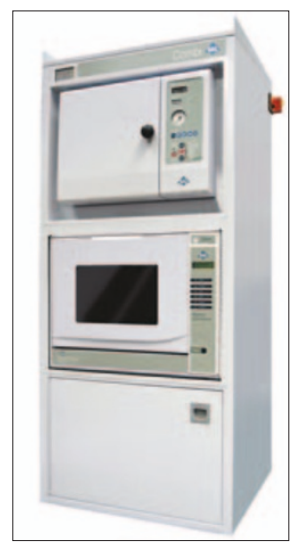

\section{TRADE NEWS}

WHAT'S NEW

\title{
Emergency use
}

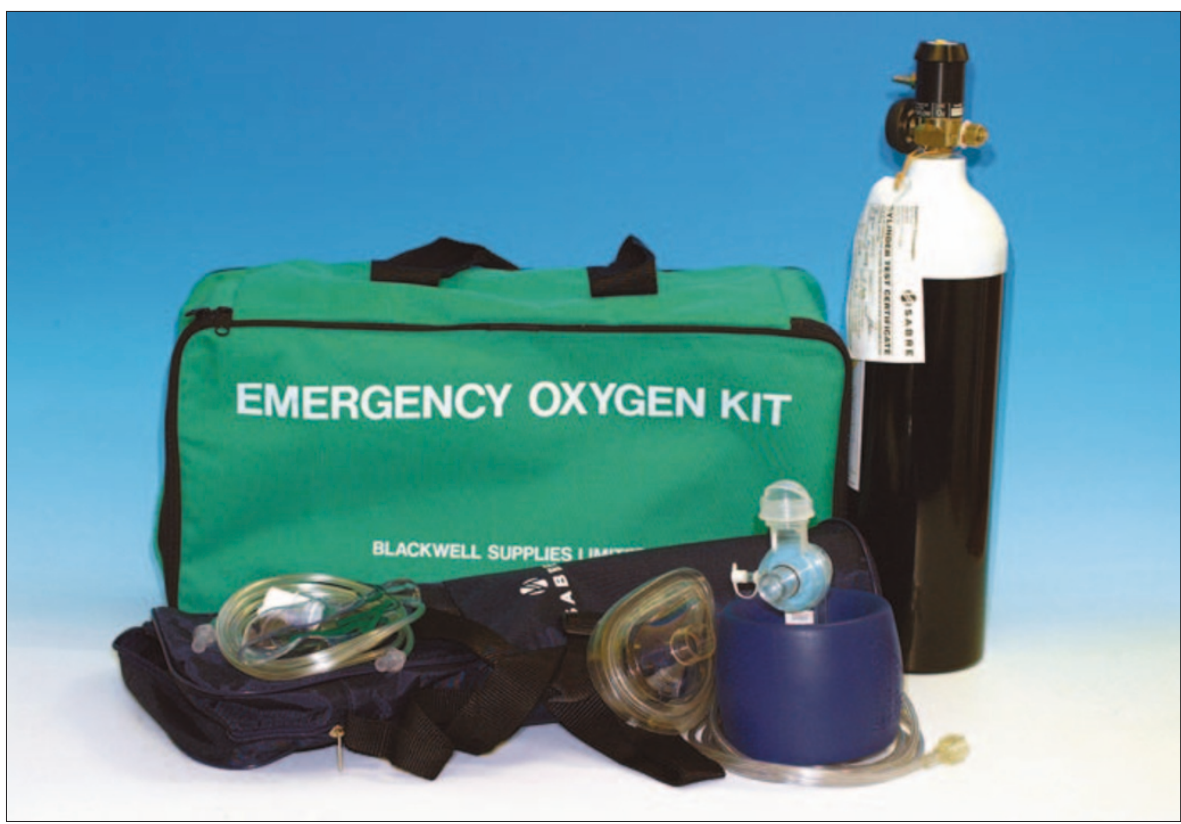

Blackwell Supplies, part of the Henry Schein group, has introduced a new emergency oxygen cylinder to provide as large a supply of oxygen in an emergency as possible.

It features a 500 Litre $\mathrm{D}$-size $\mathrm{O}_{2}$ cylinder, non-detachable 2-flow regulator (5 and 15 ipm) c/w tubing connector, adult therapy mask and tubing and a single-use self-inflating resus bag with adult mask.
The company also supplies portable suction apparatus to clear the oropharynx and maintain the natural airway including a vitalograph emergency aspirator which is easy to use and maintain by any member of the dental team.

The Res-Q-Vac Manual Suction System is lightweight and provides a fast and powerful vacuum force.

Reader response number 52

\section{New range added}

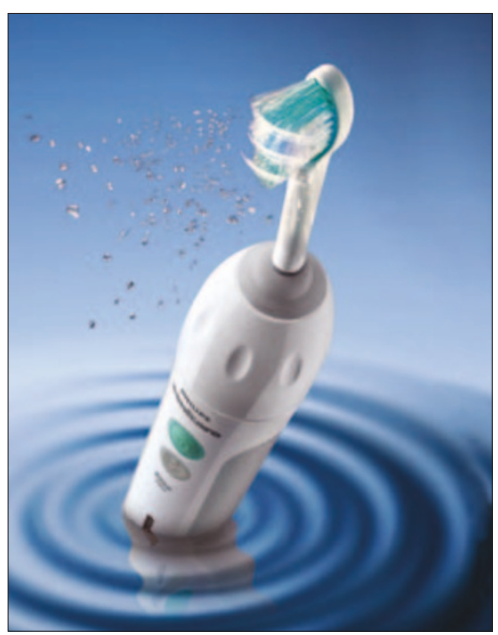

Henry Schein has added the Sonicare range of toothbrushes to its current portfolio of oral healthcare products.

The new Sonicare Elite range includes the patented sonic technology of the Sonicare Elite, which when combined with the new brush head design, creates a dynamic, fluid action.

This powerful fluid action is directed into hardto-reach areas, disrupting plaque between teeth and below the gumline.

It also features short-term stain removal that motivates patients to brush correctly and which can lead to long-term results such as reduced plaque, reduced periodontal pockets and improved gingival health.

Reader response number 53 

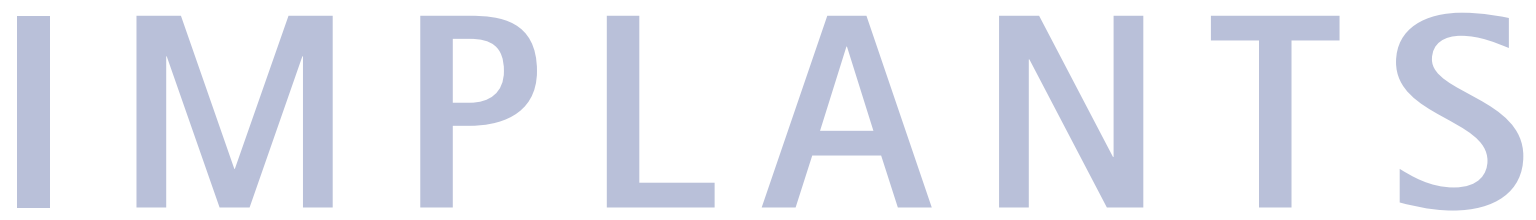

\section{One piece implant}

The Nobel Biocare one piece implant mimics natural teeth and is indicated for use in both single and multiple sites throughout the mouth.

It is machined from a single bar of titanium, incorporating both the implant body and an integral fixed abutment in one piece. The body of the implant is based on the Replace Select Tapered implant and is available in various lengths and diameters in both a scalloped and non-scalloped format. A special 3.0 diameter intended for tightspace challenges is also available.

According to Nobel Biocare, the surgery can be made flapless with minimal surgical invasion, far less discomfort for the patient and also means ease of placement for the dentist.

In addition, it features the TiUnite surface, which ensures unsurpassed initial stability as well as long term osseointegration. The surface extends above the aveolar crest on the implant supporting the formation of a normal biological width.

\section{Reader response number 54}

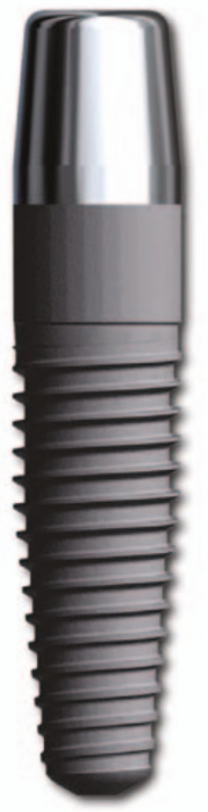

\section{Practice newsletters}

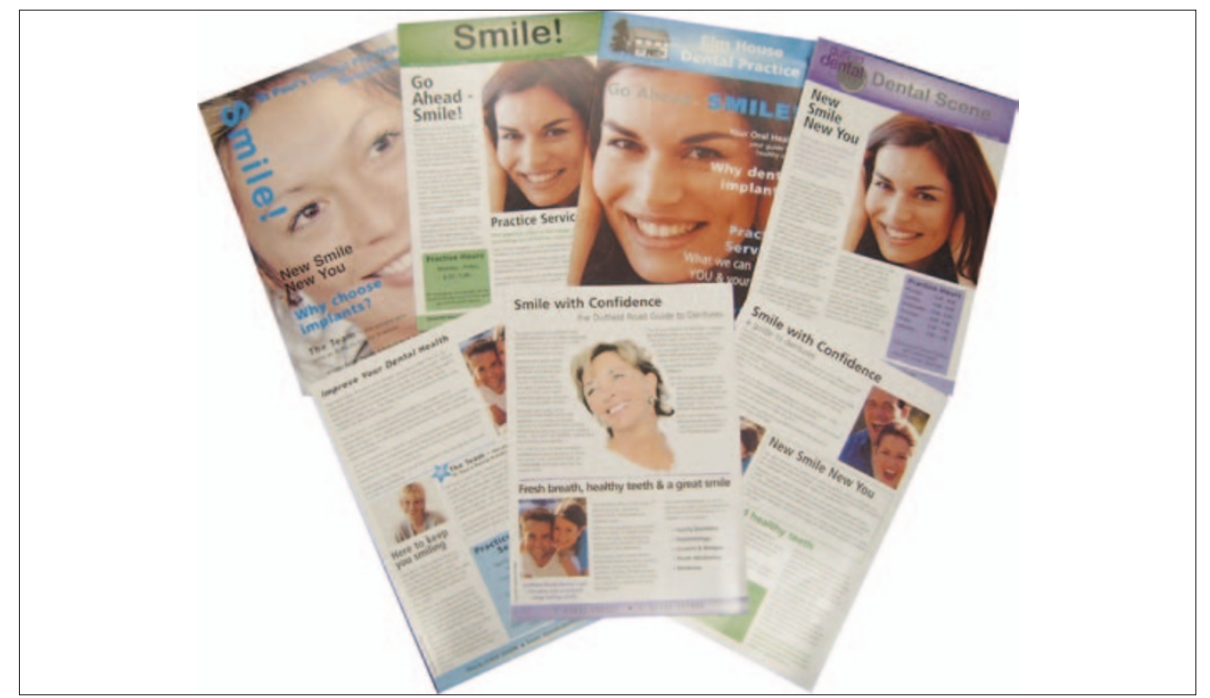

Straumann are offering a new service to its implant users.

It is providing professionally produced customised practice newsletters, which allow practices to promote their overall services on the front and back cover, whilst the inner centre section offers patients information on dental implants.

Practices can request the Newsletter Creation Form which enables them to choose pictures, layout, colours and suggested content of the front and back pages of their newsletter.

Once completed, the booking form is returned to Straumann's marketing company Manan, for creation of the customised newsletter.

For more information contact Manan Ltd on 01844299292.

Reader response number 55

\section{New addition}

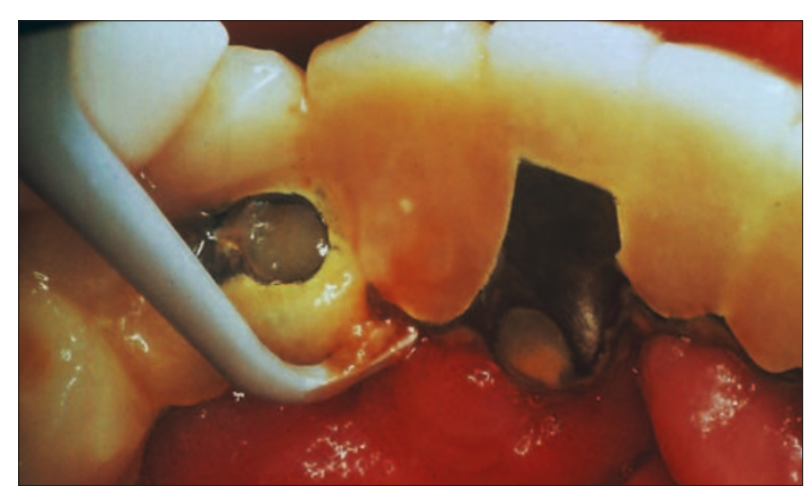

Dexcel has announced the addition of Implant Prophy+ scalers to its range.

The plastic implant scalers are manufactured from a strong, rigid plastic in a design similar to standard metal curettes.

Incorporating a long shank with a variety of tips, the scalers allow the dental team to reach previously inaccessible areas, whilst still achieving every angle desired. The entire Implant Prophy+ range is fully autoclavable to $190^{\circ}$ and every scaler in the range offers performance in the debridement of implant abutments, composite restorations and root sensitive areas.

Also included is a stone in each kit for easy sharpening, in order to prolong the working life of the scaler and reduce practice costs.

Reader response number 56 


\section{Dynamic interface}

A new bone growth catalyst has been introduced by Astra Tech. The patented OsseoSpeed process exploits the power of fluoride to encourage the growth of more bone more rapidly after implantation.

It is achieved by chemically modifying the surface of the implant with traces of fluoride, providing a dynamic interface with the surrounding bone tissue.

Astra Tech claims that the product works by generating a biological and biochemical interaction in the early healing phase after implant installation, providing increased bone formation and stronger bone-to-implant bonding.

Reader response number 57

\section{True snap set}

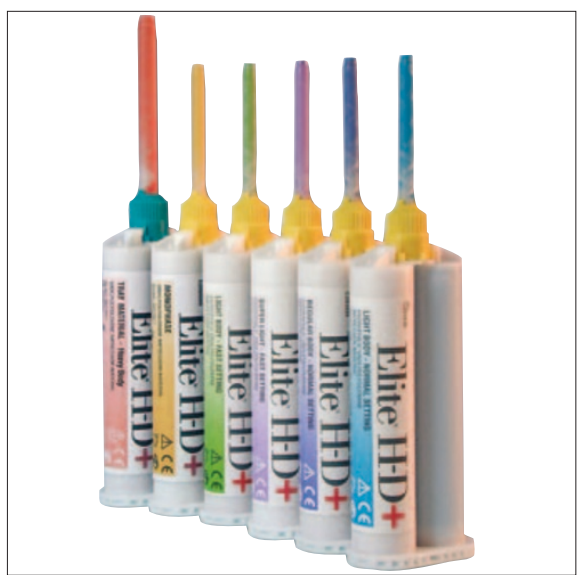

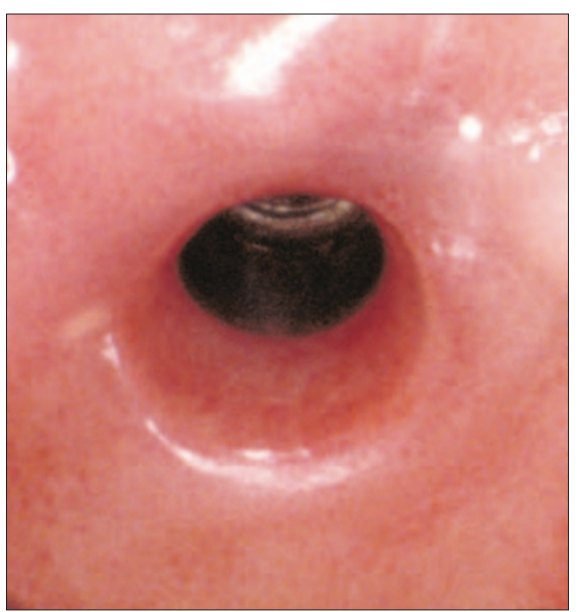

Nanotechnolgy has been incorporated into Zhermack's Elite HD+ 'A' silicone impression material range. Zhermack claim that these nanofillers improve fluidity and hydrophilic properties to enhance detail. Also, the whole range has a true snap set to minimise micro-movement and accommodate putty wash, monophase and heavy or light techniques.

Heavy and monophase viscosities also come in a format for automatic mixing machines. Samples are available from the company by telephoning 07870690811 or byemail atuk@zhermack.com.

Reader response number 58

\section{Internal hex implant system}

The IMTEC Corporation has introduced two new implant products to its range. Endure is an internal hex implant system, can be placed as a one or two-stage implant and may be used for crowns, bridges and dentures. It also offers variable implant positioning for a natural, complementary dentition.

Micro threading on the Endure implant collar preserves the cortical bone by reducing bone stress and axial stiffness while the $1 \mathrm{~mm}$ polished portion at the top offers several options in collar positioning when placing the implant.

The thread design and anatomical implant shape allow it to self-tap during insertion and minimises excessive compression stress to the bone.

The Sendax Mini-Dental Implant (MDI) system offers a one-hour, one-stage solution for denture stabilisation and long-term fixture placement. It consists of a miniature $1.8 \mathrm{~mm}$ (standard thread design) titanium alloy implant that acts like the root of a tooth and contains a retaining fixture with an 0-Ring that is incorporated into the base of a patient's denture.

The head of each implant is shaped like a ball and the retaining fixture acts like a socket. The 0-Ring snaps over the ball when the denture is seated and holds the denture at a predetermined level of force. When seated, the denture rests on the patient's gum tissue. Reader response number 59 